\title{
The efficacy of a photolyase-based device on the cancerization field: a clinical and thermographic study
}

\author{
Luigi Laino ${ }^{1}$, Fulvia Elia ${ }^{2 *}$, Flora Desiderio ${ }^{2}$, Alessandra Scarabello ${ }^{3}$, Isabella Sperduti ${ }^{4},{\text { Carlo } \text { Cota }^{5} \text { and Aldo DiCarlo }}^{6}$
}

\begin{abstract}
Background: At skin level, a cancerization field (CF) indicates some chronically photoexposed areas in which, besides a primary tumor, histological or biomolecular modifications without clinical signs are present. Active telethermography (ATT) allows us to observe the imaging of a hyperthermic halo $(\mathrm{HH})$ surrounding the tumor. The Authors hypothesize $\mathrm{HH}$ as a possible expression of CF.

Objectives: The aim of this study were to verify whether HHs have the same histological or immunohistochemical characteristics as the CF and, secondly, to evaluate the efficacy of a device containing the enzyme photolyase in modifying thermographic parameters in these area.

Methods: The study included 30 patients affected by actinic keratosis, evaluated clinically and by ATT at time 0 and after 3, 6 and 9 months.

Results: The ATT showed the presence of HHs in all the patients and, after the treatment, a significant modification of both the extension of these areas and the thermal parameters. In 5 patients for whom, while operated, two other biopsies were performed, respectively on the $\mathrm{HH}$ and on a perilesional non-hyperthermic area, in the $\mathrm{HH}$, we detected a p53 and Ki 67 over-expression.
\end{abstract}

Conclusions: Our results indicate that ATT could represent a useful paraclinic method in identifying CFs in subjects at risk.

Keywords: Cancerization field, Active telethermography, Hyperthermic halo, Skin cancer

\section{Introduction}

Actinic keratosis (AK) is one of the most frequent skin tumors, affecting in particular the Caucasian population [1-4]. Such lesions are mainly located in sun-exposed areas, i.e. head, face, and arms. Elderly people, in particular farmers and sailors, as well as individuals who have undergone immunosuppressive treatments or are chronically exposed to arsenic and tar, are at increased risk of AK $[5,6]$. Some important co-factors are, the skin phototype (type I and II according to the Fitzpatrick classification), baldness, genetic predisposition, sun exposure or burns in childhood and UV-A treatments [7-10]. Clinically, AK is characterized by erithematous or brown lesions with a

\footnotetext{
* Correspondence: fulviaelia@gmail.com

${ }^{2}$ Radiology, San Gallicano Dermatologic Institute for Research and Care, Via Elio Chianesi 53, 00144 Rome, Italy

Full list of author information is available at the end of the article
}

diameter of less than $1 \mathrm{~cm}$, showing a hyperkeratotic surface, sometimes erosive, and well-defined edges. Histologically, AK is an in situ squamous cell carcinoma (SCC) and its progression to SCC ranges from 0.25 to $16 \%$ of cases, as reported in the literature [11-13]. AK lesions are often not unique, and patients may experience new lesions in the same area, which can appear concomitant or later, in the course of the years. Moreover, in this region, the development of other malignant skin tumors such as SCC or basocellular carcinoma (BCC), after the primary AK, is also possible. This particular behavior corresponds to the concept of "cancerization field" (CF), as proposed by Slaughter in 1953 [14]. As a general characteristic, CF indicates the risk of having a second tumor in the same area after the removal of the first one. This preneoplastic condition, described initially in the oral mucosa, has 
been successively reported in internal organs and in the skin. At the cutaneous level, $C F$ is addressed to the chronically photoexposed area of the head, particularly in the fair-skinned individuals that, after a first diagnosis of AK or other non-melanoma skin cancer (NMSC), can in the future present one or more malignant lesions in the same site. Indeed, according to Slaughter [14], other Authors found some peculiar histological and biomolecular modifications in these critical areas, even in the absence of clinical signs. In fact, at the histological level, there have been reports of loss of cell polarity, disorganization, and hyper- and para-keratosis associated with dermal modifications (elastosis, vascular ectasia, reduction of collagen fibers) [15]. Immunohistochemically, some mutations of important genes e.g. p53, Bcl 212, Ki 67, p21, CPI-17, PCNA, MMP-1, and also alterations of pro-collagen 1 and tenascin- $C$ have been demonstrated $[16,17]$. In addition, in experimental models, some Authors have described, the production of a high number of cyclobutane pyrimidine dimers (CPD), the major DNA photoproducts of UV radiations, in the CF [18].

Given the foregoing, the study of CF is very important for the monitoring of individuals already treated for AK, with the aim of preventing a second tumor. To this purpose, many non-invasive methods have been employed in order to identify these areas at risk, such as dermoscopy and confocal microscopy $[19,20]$. Also, mathematical models have been proposed [21]. Telethermography (TT) is a non-invasive method that collects the infrared radiation emitted from the body and creates an electronic image [22, 23]. Since its first description by Brasfield [24], many Authors have observed that malignant tumors of the skin, such as melanoma and SCC, show a "hot" pattern, while benign lesions (e.g. seborrheic warts), and BCC appear as "cold" [24, 25]. In those area, thermal values, particularly in large nodular forms, could reach even $3-4{ }^{\circ} \mathrm{C}$. However, if the tumoral lesions are small (e.g. diameter $<1 \mathrm{~cm}$ ), they could be thermographically undetectable or "missed" (as Brasfield first noted) [24], particularly when the lesions are sited in physiological "hot" regions (e.g. groin, axilla) (false negatives). The principle of dynamic or active telethermography (ATT) is that, by cooling or heating by air or by gel packs the skin for a defined period of time, is possible to better observe the specific pattern of the tumor. This pattern appears rapidly (in seconds) in the course of the thermal recovering of the area after the removal of the stimulation, in contrast with the thermal recovery of the perilesional healthy skin (in minutes) $[25,26]$. The thermal recovery time (TRT) is the interval between $t^{0}$ and the time that single thermal points come back to the steady state (expressed in seconds, or minute). The first advantage of the method is the possibility to evaluate very small malignant lesions that, having a reduced critical mass, are difficult to observe using direct thermography. Furthermore, thermostimulation does not require climatizing of the operating room, the thermal recovery being independent of the normal working conditions of the room. In melanoma studies, we found TT useful for the diagnosis of in-transit metastases from melanoma $[27,28]$. Some methods use a periodic thermal modulation, e.g. lock-in thermal imaging (LIT) [29].

Introducing the "thermostimulation" method in 1995, our intent was to perform a thermal stress under controlled conditions, and following the transient temperature measurement [30]. By selecting the infrared imaging at a specific time after thermostimulation, it is possible to "reject" the effect of local steady state and to select the peculiar thermographic pattern of the lesions. For this procedure, a special equipment has been adopted, namely the thermostimulator (Reg. Italy. Patent 1323870/IT/2001) [29] (see Methods). In a recent paper, we demonstrate by using ATT that AK has not only a "hot" pattern and a rapid TRT but it is surrounded by a hyperthermic halo $(\mathrm{HH})$, whose thermal intensity $(\Delta \mathrm{t})$ appears lower than that of the tumor. This $\mathrm{HH}$ expands generally for $2-4 \mathrm{~cm}^{2}$ around the clinical lesion [30].

On these premises, our hypothesis was that $\mathrm{HH}$ could correspond to the CF. To demonstrate this, the aim of this study was to verify whether, in the $\mathrm{HH}$ area were present, at histological and immunohistochemical level, the same changes present in the $\mathrm{CF}$, as reported in literature [30-32]. Furthermore, we proposed to verify by this method the efficacy of the compound Eryfotona ${ }^{R}$ in reducing the degree and the extension of the $\mathrm{HH}$. Eryfotona is a film-forming medical device in fluid formulation containing a DNA-repair enzyme photolyase and a high-protection UV filter (Repairsomes ${ }^{\mathrm{TM}}$ ) that is indicated in the treatment of CF in patients affected by AK. Previous studies have shown that Eryfotona is effective in treating and preventing the abnormal histological and biomolecular cellular pattern of CF [31-35].

\section{Patients and methods}

\section{Patients and Eryfotona treatment}

A group of 30 patients affected by AK, respectively 27 males and 3 females, referred to our Institute in the period January-April 2013. The age ranged from 55 to 75 years $($ mean $=64.3$ years). All the patients had phototype I-II, and a personal history of prolonged exposure to sun rays, for professional or recreational reasonsrespectively 14 farmers, 4 sailors, 4 lifeguards, while the other 8 lived near the sea. Most of them (27/30 patients) had baldness at an advanced stage, while all female 
patients had androgenic alopecia with severe baldness in the temporo-frontal region. The AK lesions were mainly sited in the temporo-parietal, frontal and occipital regions.

Treatment with Eryfotona started 15 days after surgical removal of the lesions. Eryfotona was applied daily (at 8 and $12 \mathrm{~h}$ ) by the patient in the areas concerned, at a standard dose for 9 months. Written informed consent was obtained from all patients, and the study was approved by the institutional research board and conducted according to the Declaration of Helsinki Principles. Three drop-outs for poor compliance (Patients n 7, 8, 10) were reported.

\section{Active telethermography (ATT)}

For this procedure we employed a FLIR3000 Thermo$\mathrm{cam}^{\mathrm{ma}}$ together with the thermostimulation method. We used a special equipment, namely the thermostimulator (Reg. Italy. Patent 1323870/IT/2001) [29] consisting of a small insulated tank containing $5 \mathrm{l}$ of a mixture of alcohol and water at $50 \%$ and connected through a two-way tube to the probe, a rubber balloon with a capacity of $250 \mathrm{ml}$. The mixture can be led to a preset temperature, by means of a heating-cooling system put inside the walls of the tank (range possibility: from $0{ }^{\circ} \mathrm{C}$ to $40{ }^{\circ} \mathrm{C}$ ). The temperature of the liquid in the container and the time of application are displayed on monitors. After the mixture reaches the set temperature (in our study: $+5{ }^{\circ} \mathrm{C}$ ), the liquid is driven at high speed by means of the pump to fill the balloon. Then, the balloon is rested on the skin for $20 \mathrm{~s}$. The moment when stress is removed $\left(=t^{0}\right)$, the whole stimulated skin area has homogenously a thermal value of $+5{ }^{\circ} \mathrm{C}$. The area of the hyperthermic halo $(\mathrm{HH})$ is automatically calculated by a simple function of the PC connected with the thermocamera. To ensure that the same skin surface is observed at each examination, we used a specific function of the PC connected to the thermocamera, and in case of several lesions, a cutaneous marker was used. Thermal recovery time (TRT) is the interval between $t^{0}$ and the time that single thermal points come back to the steady state (expressed in seconds, or minute). Clinical and thermographic evaluations were planned respectively at time 0 , and 3, 6 and 9 months of treatment. TRT was considered as rapid (R) for values $<10 \mathrm{~s}$, slow $(\mathrm{S})$ for values $>10 \mathrm{~s}$ and $<2 \mathrm{~min}$, and normal $(\mathrm{N})$ for values of healthy perilesional skin $(>2 \mathrm{~min})$.

\section{Immunohistochemistry}

In 5 of the subjects $(n=30)$, two punch biopsies were also performed during the surgical removal of AK, respectively, one in the area of $\mathrm{HH}$ and the other in a perilesional non-hyperthermic area. All specimens were processed using the standard histopathologic method of paraffin embedding sectioning and hematoxylin-eosin (HE) staining. In these 5 patients, in addition to histological evaluation, an immunohistochemical test for p53 and Ki67 was also conducted.

\section{Statistical analyses}

Descriptive statistics were used to represent study results as percentages and medians (range). A Friedman test for non-parametric data was used to test changes in each variable over time, while a McNemar test was used for paired data. The SPSS (21.0) statistical program was used for analysis.

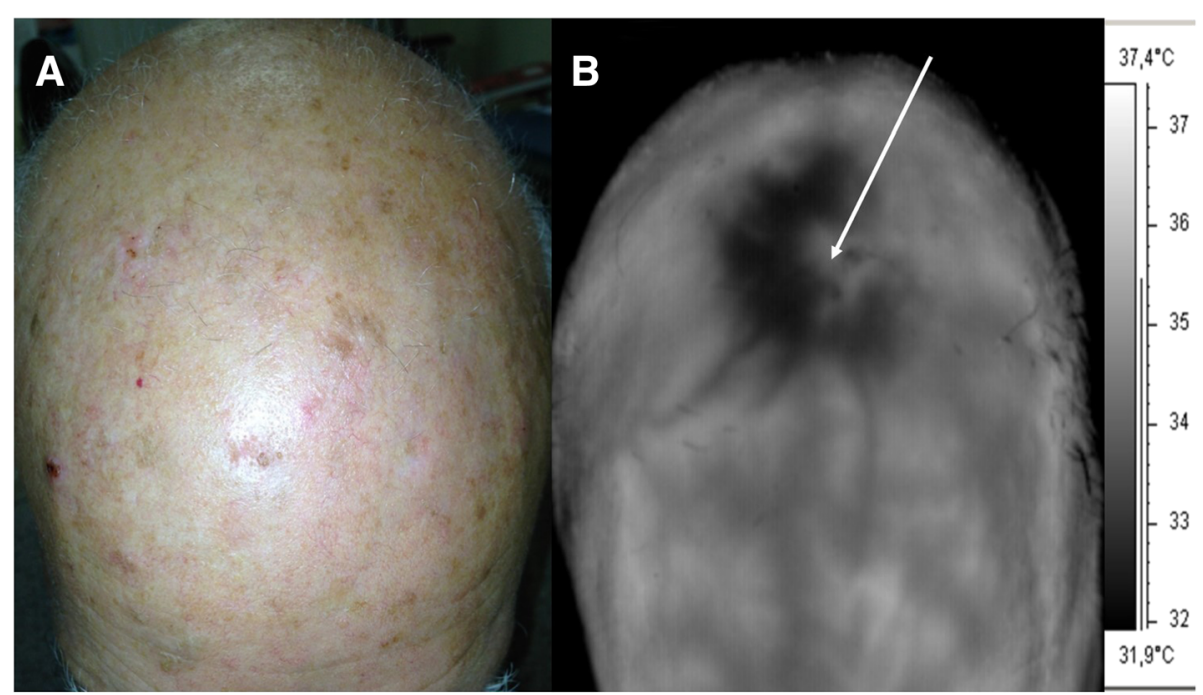

Fig. 1 a AK of the scalp. b TTG of the scalp. Note the hyperthermic "halo", while squamous crusts make the AK lesion itself apparently "cold" 


\section{Results}

The thermographic presence of $\mathrm{HH}$ was observed in all the patients before the surgical removal of AK. These $\mathrm{HHs}$ extended from few $\mathrm{mm}^{2}$ to some $\mathrm{cm}^{2}$ (mean $3.46 \mathrm{~cm}^{2}$ ), and their TRTs, very rapid at baseline, showed generally progressive increase at each control (Fig. 1 and Table 1). In the 27 patients that completed the study, after treatment with Eryfotona we observed that the area of the HHs declined from a mean of $3.46 \mathrm{~cm}^{2}$ at baseline to a mean of $0.64 \mathrm{~cm}^{2}$ at 9 months, while the values of TRT progressively increased toward the perilesional values of the healthy skin ( $>2 \mathrm{~min}$ ) (Table 1$)$. In 5 cases, the $\mathrm{HH}$ disappeared completely. In parallel, at each periodic control, the TRT values showed a progressive tendency to the same values as the perilesional healthy skin. In those 5 patients in which a double biopsy was performed, in the $\mathrm{HH}$ site, we observed, histologically, a more or less marked actinic elastosis and p53 and Ki 67 overexpression in the epidermis (Fig. 2). These data were less evident or absent in the non-hyperthermic perilesional site (data not shown).

\section{Discussion}

The term "cancerization field" (CF) was initially introduced by Slaughter for describing the presence in the oral cavity of some histological alterations besides or

Table 1 Evolution of the hyperthermic halo $(\mathrm{HH})$ in 27 patients. The diagram shows, respectively, its extension (in $\mathrm{cm}^{2}$ ) and RTR

\begin{tabular}{|c|c|c|c|c|c|c|c|c|c|}
\hline \multirow[b]{2}{*}{ Patient } & \multirow[b]{2}{*}{ Lesion site } & \multicolumn{2}{|l|}{ Baseline } & \multicolumn{2}{|c|}{ I Check (3 Months) } & \multicolumn{2}{|c|}{ II Check (6 Months) } & \multicolumn{2}{|c|}{ III Check (9 Months) } \\
\hline & & $\begin{array}{l}\text { HH Area } \\
\left(\mathrm{cm}^{2}\right)\end{array}$ & $\begin{array}{l}\text { TRT } \\
\text { (a) }\end{array}$ & $\begin{array}{l}\mathrm{HH} \text { Area } \\
\left(\mathrm{cm}^{2}\right)\end{array}$ & TRT & $\begin{array}{l}\mathrm{HH} \text { Area } \\
\left(\mathrm{cm}^{2}\right)\end{array}$ & TRT & $\begin{array}{l}\text { HH Area } \\
\left(\mathrm{cm}^{2}\right)\end{array}$ & TRT \\
\hline 1 & Frontotemporal & 5 & $\mathrm{R}$ & 4 & $\mathrm{R}$ & 2 & $\mathrm{R}$ & 1 & S \\
\hline 2 & Frontoparietal & 4 & R & 3 & $\mathrm{R}$ & 1 & S & 0,5 & S \\
\hline 3 & Frontoparietal & 4 & R & 3 & R & 1 & R & 0,5 & S \\
\hline 4 & Temporal & 3 & $\mathrm{R}$ & 2 & $\mathrm{R}$ & 1 & S & 1 & S \\
\hline 5 & Frontotemporal & 3 & $\mathrm{R}$ & 2 & $\mathrm{R}$ & 1 & $R$ & 0 & N \\
\hline 6 & Occipital & 5 & R & 4 & $\mathrm{R}$ & 1 & $\mathrm{R}$ & 0 & $\mathrm{~N}$ \\
\hline 7 & Occipital & 4 & $\mathrm{R}$ & 3 & $\mathrm{R}$ & Drop-out & & & \\
\hline 8 & Occipital & 3 & R & 2 & $\mathrm{R}$ & 2 & $\mathrm{R}$ & Drop-out & \\
\hline 9 & Temporal & 5 & $\mathrm{R}$ & 3 & $\mathrm{R}$ & 1 & $\mathrm{R}$ & 1 & S \\
\hline 10 & Frontoparietal & 4 & $\mathrm{R}$ & 3 & $\mathrm{R}$ & Drop-out & & & \\
\hline 11 & Occipital & 3 & R & 2 & S & 1 & S & 0 & $\mathrm{~N}$ \\
\hline 12 & Frontal & 2 & R & 2 & R & 1 & S & 1 & S \\
\hline 13 & Parietal & 5 & $R$ & 4 & $\mathrm{R}$ & 3 & $\mathrm{R}$ & 1 & S \\
\hline 14 & Occipital & 3 & $\mathrm{R}$ & 2 & $\mathrm{R}$ & 1 & $\mathrm{R}$ & 0,5 & S \\
\hline 15 & Occipital & 2 & R & 1 & $\mathrm{R}$ & 0,5 & $\mathrm{~N}$ & 0 & $\mathrm{~N}$ \\
\hline 16 & Frontotemporal & 3 & $R$ & 2 & $\mathrm{R}$ & 1 & $\mathrm{~N}$ & 1 & $\mathrm{R}$ \\
\hline 17 & Frontoparietal & 4 & $\mathrm{R}$ & 3 & $\mathrm{R}$ & 2 & $\mathrm{R}$ & 1 & $\mathrm{R}$ \\
\hline 18 & Parieto-temporal & 2 & $\mathrm{R}$ & 1 & R & 1 & $R$ & 0,5 & S \\
\hline 19 & Temporal & 4 & R & 3 & R & 2 & N & 0,5 & S \\
\hline 20 & Frontotemporal & 4 & $\mathrm{R}$ & 3 & $\mathrm{R}$ & 2 & $\mathrm{R}$ & 0,5 & S \\
\hline 21 & Temporo-occipital & 2 & $R$ & 1 & $\mathrm{R}$ & 1 & $\mathrm{R}$ & 0,5 & S \\
\hline S22 & Frontoparietal & 3 & $\mathrm{R}$ & 2 & S & 1 & S & 1 & S \\
\hline 23 & Occipital & 4 & $\mathrm{R}$ & 3 & S & 2 & S & 1 & $\mathrm{R}$ \\
\hline 24 & Temporal & 5 & $\mathrm{R}$ & 4 & $\mathrm{R}$ & 3 & $\mathrm{R}$ & 0,8 & SN \\
\hline 25 & Frontoparietal & 3 & $\mathrm{R}$ & 2 & $\mathrm{R}$ & 1 & S & 0,5 & SN \\
\hline 26 & Occipital & 2 & R & 1 & S & 0,5 & S & 0,5 & S \\
\hline 27 & Frontal & 2 & $\mathrm{R}$ & 1 & $\mathrm{R}$ & 1 & S & 0,6 & S \\
\hline 28 & Parietal & 3 & R & 2 & $\mathrm{R}$ & 1 & R & 0,5 & S \\
\hline 29 & Occipital & 4 & R & 3 & $\mathrm{R}$ & 2 & $R$ & 1 & $S$ \\
\hline 30 & Frontal & 4 & $\mathrm{R}$ & 3 & $\mathrm{R}$ & 2 & $\mathrm{R}$ & 0 & $\mathrm{~N}$ \\
\hline
\end{tabular}

(a)TRT = Thermal recovery times. Rapid (<10 s): Slow (>10 s $<2$ min); Normal $(>2$ ') 


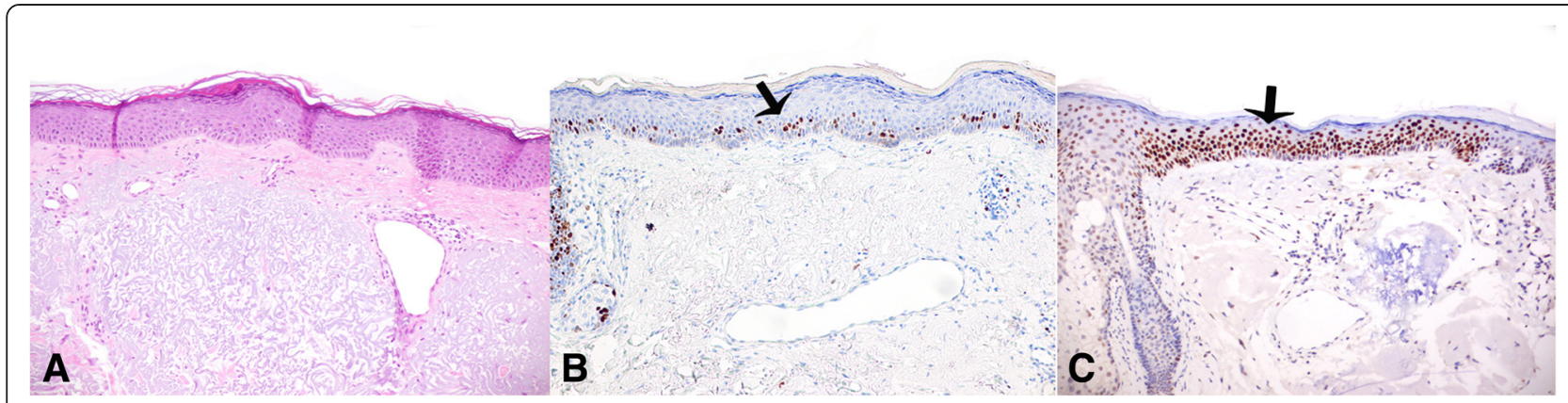

Fig. 2 a Histologic examination of skin biopsy from cancerization field. The epidermis appears normal without evident atypia of the keratinocytes. In the dermis, marked actinic elastosis is present. b Proliferating cell in suprabasal layers, as marked with Ki67. c p53 expression of the epidermis in corresponding area of cancerization field (arrow)

near the primary tumor, in the absence of clinical evidence. For this reason, he expressed the concept of CF as a "benign epithelium preconditioned to change toward cancer" [14]. The possibility of a gradual progression from subclinic condition to a clinically detectable SCC was also confirmed by other Authors [15-18]. At skin level, the most significant example of $\mathrm{CF}$ is considered the sunexposed areas of individual at risk, in which also AKs and other NMSC are frequently observed. Among noninvasive methods proposed to identify these areas, the ATT method uniquely allow us to observe in imaging the presence of the $\mathrm{HH}$ that could be the visible expression of CF. Thermographically, $\mathrm{HH}$ is defined as a hyperthermic halo surrounding the AK lesion. Its identification is possible by means of ATT that shows its quick thermal recovery and its particular morphology (asymmetric hyperthermic halo). Introducing the "thermostimulation" method in 1995, our intent was to perform a thermal stress under controlled conditions, and following the transient temperature measurement [29]. In our previous studies, based always on the same parameters $\left(+5^{\circ} \mathrm{C} \times 20^{\prime \prime}\right)$, we report a value of TRT $>2 \mathrm{~min}$ in the case of healthy skin, in agreement with others [25, 26]. On an average evaluation, the thermal difference among tumor, $\mathrm{HH}$ and perilesional healthy skin, are often $<0.01^{\circ} \mathrm{C}$, leading to "miss" these hot spot being low the current accuracy/sensitivity of the ATT devices for this purpose. The thermostimulation method let us to easily overpass the problem of the direct ATT by switching the thermographic static values (in ${ }^{\circ} \mathrm{C}$ ) with the times of recovery expressed in $\mathrm{min} / \mathrm{s}$. TRTs in case of malignant tumor are in general of the order of second, while those of the healthy are in the order of minutes, according to our parameters of thermal stress $\left(+5{ }^{\circ} \mathrm{C} \times 20^{\prime \prime}\right)$. In our observations, $\mathrm{HH}$ has a less rapid thermal recovery respect to the tumor as it is reported in the Table 1 . In the case of malignant tumors of the skin, such as SCC and malignant melanoma, we observe, few seconds after $t^{0}$, the thermal image of the tumor as a hot spot, while residual field is still cold $[25,26]$. However, in cases of basocellular carcinoma, we have noted a long persistence of hypothermia after the thermostimulation (an order of minutes) as happens also for other pigmented benign lesions (e.g. seborrheic warts) [29]. The molecular mechanisms of $\mathrm{HH}$ are not clear. Possible explanation has be suggested to be the high esothermic metabolism of the malignant tumors in contrast to other lesions such as basalioma [26]. In agreement with this hypothesis, we found, in the 5 cases in which we performed the perilesional biopsies, overexpression of Ki 67 and p53, the latter indicative of gene mutation, particularly in the correspondence of $\mathrm{HH}$ that is suggestive of tumor transformation. Recent studies in molecular genetics hypothesize a carcinogenetic model based on the clonal expansion of genetically modified cells following the chronic action of UV radiations. In particular, DNA-modifying UV-A and, to greater degree, UV-B and RNA structure foster the formation of CPD with subsequent mutations of the telomerase or oncosuppressor p53 gene [19]. However, to confirm our hypothesis, it is necessary to have more data, in particular, a larger number of patients and samples.

The reason for the enrolment of a small number of patients to evaluate the histological and immunohistochemical studies of $\mathrm{HH}$ (5 subjects) was due to the fact that the principal end-point of this paper was to confirm by means of ATT the presence of HH in all the patients affected by AK. Then, we performed the immunohistochemical tests only in those patients that consented to more biopsies. Eryfotona ${ }^{\mathrm{R}}$ proved effective in reducing the extension of HHs and their thermal values in our 27 subjects after a treatment of 9 months. The mechanism of action of Eryfotona is dual, a preventive one of the UV-block by means of a strong sunscreen and a molecular enzymatic action on DNA (photolyase). Furthermore, topical application of liposome formulations with CPD 
photolyases onto human skin provides protection against UVB-induced damage [36-37]. Finally, patients declared, from the first control, a sharp reduction, in most cases a complete resolution, of the itchiness and/or pain referred to the lesional and perilesional area.

In conclusion, among the non-invasive methods from time to time proposed in the study of CF, ATT could represent a useful paraclinic method in identifying CF in subjects at risk. Thermography has a long story in clinical applications, but thermal imaging in dermatology is not much employed and the papers on this issue are very few among dermatologists, the specialists that could benefit most in this field. This method is easy to use, gives an immediate response, and is repeatable and reproducible. For this reason, ATT could be very useful for epidemiological controls in some groups at risk, in the follow-up of operated patients, and in the assessment of the efficacy of proposed treatments.

\section{Abbreviations}

AK: Actinic keratosis; ATT: Active telethermography; BCC: Basocellular carcinoma; CF: Cancerization field; CPD: Cyclobutane pyrimidine dimmers; HE: Hematoxylin-eosin; HH: Hyperthermic halo; LIT: Lock-in thermal imaging; NMSC: Non-melanoma skin cancer; SCC: Squamous cell carcinoma; TRT: Thermal recovery time.

\section{Competing interest}

The authors declare that they have no competing interests.

\section{Authors' contributions}

$\mathrm{LL}$ and AS enrolled patients. CC carried out biopsies and molecular studies. FE and FD conducted thermographic studies. IS realized the statistical analysis. ADC conceived the study, and participated in its design and coordination, and helped to draft the manuscript. All authors read and approved the final manuscript.

\section{Acknowledgements}

We would like to thank the patients who participated in this study. No financial support was received for this study.

\section{Author details \\ ${ }^{1}$ Thermography, San Gallicano Dermatologic Institute for Research and Care, Via Elio Chianesi 53, 00144 Rome, Italy. ${ }^{2}$ Radiology, San Gallicano Dermatologic Institute for Research and Care, Via Elio Chianesi 53, 00144 Rome, Italy. ${ }^{3}$ Clinical Dermatology, San Gallicano Dermatologic Institute for Research and Care, Via Elio Chianesi 53, 00144 Rome, Italy. ${ }^{4}$ Biostatistical Unit, IFO-Regina Elena National Cancer Institute for Research and Care, Via Elio Chianesi 53, 00144 Rome, Italy. ${ }^{5}$ Dermopathology, San Gallicano Dermatologic Institute for Research and Care, Via Elio Chianesi 53, 00144 Rome, Italy. ${ }^{6}$ Scientific Director, San Gallicano Dermatologic Institute for Research and Care, Via Elio Chianesi 53, 00144 Rome, Italy.}

Received: 24 June 2015 Accepted: 10 August 2015

Published online: 19 August 2015

\section{References}

1. Cakir BÖ, Adamson P, Cingi C. Epidemiology and economic burden of non melanoma skin cancer. Facial Plast Surg Clin North Am. 2012;4:419-22.

2. Holmes C, Foley P, Freeman M, Chong AH. Solar keratosis: Epidemiology, pathogenesis, presentation and treatment. Australas J Dermatol. 2007:48:67-76.

3. Ouyang YH. Skin Cancer of the Head and Neck. Semin Plast Surg. 2010;24:117-26.

4. Roewert-Huber J, Stockfleth E, Kerl H. Pathology and pathobiology of actinic (solar) keratosis - an update. Br J Dermatol. 2007;157:18-20.

5. Mcintyre WJ, Downs MR, Bedwell SA. Treatment options for actinic keratoses. Am Fam Physician. 2007;76:667-71.
6. Naldi L, Chatenoud L, Picciotto R, Colombo P, Placchesi EB, La Vecchia C. Prevalence of actinic keratoses and associated factors in a representative sample of the Italian adult population: Results from the Prevalence of Actinic Keratoses Italian Study, 2003-2004. Arch Dermatol. 2006;142:722-6.

7. Berman B, Cockerell CJ. Pathobiology of actinic keratosis: ultraviolet-dependent keratinocyte proliferation. J Am Acad Dermatol. 2013;68:10-9.

8. Flohil SC, Van der Leest RJ, Dowlatshahi EA, Hofman A, de Vries E, Nijsten T. Prevalence of actinic keratosis and its risk factors in the general population: the Rotterdam Study. J Invest Dermatol. 2013;133:1971-8.

9. Traianou A, Ulrich M, De Apalla Z, Vries E, Bakirtzi K, Kalabalikis D, et al. Risk factors for actinic keratosis in eight European centres: a case-control study. Br J Dermatol. 2012;167:36-42.

10. Khalesi M, Whiteman DC, Doi SA, Clark J, Kimlin MG, Neale RE. Cutaneous markers of photo-damage and risk of Basal cell carcinoma of the skin: a meta-analysis. Cancer Epidemiol Biomarkers Prev. 2013;22:1483-9.

11. Zalaudek I, Giacomel J, Schmid K, Bondino S, Rosendahl C, Cavicchini S, et al. Dermatoscopy of facial actinic keratosis, intraepidermal carcinoma, and invasive squamous cell carcinoma: a progression model. J Am Acad Dermatol. 2012;66:589-97.

12. Ratushny V, Gober MD, Hick R, Seykora JT. From keratinocyte to cancer: the pathogenesis and modelling of cutaneous squamous cell carcinoma. Clin Invest. 2012;122:464-72.

13. Anwar J, Wrone DA, Kimyai-Asadi A, Alam M. The development of actinic keratosis into invasive squamous cell carcinoma: evidence and evolving classification schemes. Clin Dermatol. 2004;22:189-96.

14. Slaughter DP, Southwick HW, Smejkal W. Field cancerization in oral stratified squamous epithelium. Cancer. 1953;6:963-8.

15. Braakhuis BJ, Tabor MP, Kummer JA, Leemans CR, Brakenhoff RH. A genetic explanation of Slaughter's concept of field cancerization: evidence and clinical implications. Cancer Res. 2003;63:1727-30.

16. Torezan LA, Festa-Neto C. Cutaneous field cancerization: clinical, histopathological and therapeutic aspects. Ann Bras Dermatol. 2013;88:775-86.

17. Szeimies RM, Torezan L, Niwa A, Valente N, Unger P, Kohl E, et al. Clinical, histopathological and immunohistochemical assessment of human skin field cancerization before and after photodynamic therapy. Br J Dermatol. 2012;167:150-9.

18. Chai H, Brown RE. Field effect in cancer-an update. Ann Clin Lab Sci. 2009;39:331-7.

19. Durbeej B, Eriksson LA. On the formation of cyclobutane pyrimidine dimmers in UV-irradiated DNA: Why are thymines more reactive? Photochem Photobiol. 2003;78:159-67.

20. Ulrich M, Krueger-Corcoran D, Roewert-Huber J, Sterry W, Stockfleth E, Astner S Reflectance confocal microscopy for noninvasive monitoring of therapy and detection of subclinical actinic keratosis. Dermatology. 2010;220:15-24.

21. Malvehy J. A new vision of actinic keratosis beyond visible clinical lesions. J Eur Acad Dermatol Venereol. 2015;29:3-8.

22. Foo J, Leder K, Ryser L. Multifocality and recurrence risk: A quantitative model of field cancerization. J Theoretical Biol. 2014;355:170-84.

23. Vollmer M, Mollmann K-P. Infrared thermal imaging: fundamentals, research and applications. WILEY-VCH Verlag GmbH \& Co. KGaA; 2010. Weinheim ISBN: 978-3-527-40717-0.

24. Brasfield RD, Laughlin JS, Sherman KS. Thermography in the management of cancer: A preliminar report. Ann NY Acad Sci. 1964;121:235-47.

25. Herman C, Pirtini Cetingul M. Quantitative visualization and detection of skin cancer using dynamic thermal imaging. J Vis Exp. 2011. doi:10.3791/2679.

26. Buzug TM, Schumann S, Pfaffmann L, Reinhold U, Ruhlmann J. Functional infrared imaging for skin-cancer screening. Conf Proc IEEE Eng Med Biol Soc. 2006;1:2766-9.

27. Solivetti FM, Desiderio F, Guerrisi A, Bonadies A, Maini CL, Di Filippo S, et al. HF ultrasound vs PET-CT and telethermography in the diagnosis of In-transit metastases from melanoma: a prospective study and review of the literature. J Exp Clin Cancer Res. 2014;33:96.

28. Solivetti FM, Elia F, Guerrisi A, Desiderio F, Santaguida M, Sperduti I, et al. Cutaneous melanoma follow-up: appropriateness of requests for ultrasound tests-the S.Gallicano National Referral Centre Experience. J Exp Clin Cancer Res. 2013;32:73.

29. Bonmarin M, Le Gal FA. Lock-in thermal imaging for the early-stage detection of cutaneous melanoma: A feasibility study. Comput Biol Med. 2014;47:36-43. 
30. Di Carlo A. Thermography and the possibilities for its applications in clinical and experimental dermatology. Clin Dermatol. 1995;13:329-36.

31. Di Carlo A, Elia F, Desiderio F, Catricalà C, Solivetti FM, Laino L. Can video-thermography improve differential diagnosis and therapy between basal cell carcinoma and actinic keratosis? Dermatol Ther. 2014:27:290-7.

32. Puviani M, Barcella A, Milani M. Efficacy of a photolyase-based device in the treatment of cancerization field in patients with actinic keratosis and non-melanoma skin cancer. G Ital Dermatol Venereol. 2013;148:693-8.

33. Giustini S, Miraglia E, Berardesca E, Milani M, Calvieri S. Preventive long-term effects of a topical film-forming medical device with ultra-high UV protection filters and DNA repair enzyme in Xeroderma Pigmentosum: A retrospective study of eight cases. Case Rep Dermatol. 2014;6:222-6.

34. Puig S, Puig-Butillé JA, Díaz MA, Trullas C, Malvehy J. Field cancerisation improvement with topical application of a film-forming medical device containing photolyase and UV filters in patients with actinic keratosis, a pilot study. J Clin Exp Dermatol Res. 2014:5:3

35. Puig-Butillé JA, Malvehy J, Potrony M, Trullas C, Garcia-García F, Dopazo J, et al. Role of CPI-17 in restoring skin homoeostasis in cutaneous field of cancerization: effects of topical application of a film-forming medical device containing photolyase and UV filters. Exp Dermatol. 2013;22:494-6.

36. Piaserico S, Milani M. Efficacia clínica della fotoliasi tópica dopo terapia fotodinámica in soggetti con cheratosi attinica: studio prospettico randomizzato intrapaziente. Giorn It Dermatol Venereol. 2012;147:109.

37. Thoma F. Light and dark in chromatin repair: repair of UV-induced DNA lesions by photolyase and nucleotide excision repair. EMBO J. 1999;18:6585-98.

\section{Submit your next manuscript to BioMed Central and take full advantage of:}

- Convenient online submission

- Thorough peer review

- No space constraints or color figure charges

- Immediate publication on acceptance

- Inclusion in PubMed, CAS, Scopus and Google Scholar

- Research which is freely available for redistribution 